Electronic supplementary information for

\title{
Defect-Abundant Covalent Triazine Frameworks as Sunlight-Driven Self-Cleaning Adsorbents for Volatile Aromatic Pollutants in Water
}

Yi Shen ${ }^{1}$, Chao Zhu ${ }^{1}$, Shuang Song ${ }^{1}$, Tao Zeng ${ }^{1,2^{*}}$, Lingxiangyu $\mathrm{Li}^{3}$, Zongwei Cai ${ }^{2}$

1. Key Laboratory of Microbial Technology for Industrial Pollution Control of

Zhejiang Province, College of Environment, Zhejiang University of Technology, Hangzhou 310032, P. R. China

2. State Key Laboratory of Environmental and Biological Analysis, Department of Chemistry, Hong Kong Baptist University, Hong Kong SAR, P. R. China

3. Department of Chemistry, School of Sciences, Zhejiang Sci-Tech University, Hangzhou 310018, P. R. China 
${ }^{*}$ Corresponding Author

Dr. Tao Zeng. Email: zengtao@zjut.edu.cn; Fax: +86-571-88320276; Tel: +86-571-88320726.

Preparation of CTF-1, CTF-2, CTF-m and CTF-mi. CTF-1 was synthesized as the procedure below. 1,4-dicyanobenzene (4 mmol, J\&K Chemical) was dissolved in the $\mathrm{CF}_{3} \mathrm{SO}_{3} \mathrm{H}(2.5 \mathrm{~mL})$ under nitrogen at $0{ }^{\circ} \mathrm{C}$. After stired for $1.5 \mathrm{~h}$ in an ice-water bath, the obtained viscous solution was kept at $100{ }^{\circ} \mathrm{C}$ for 20 minutes in an oven. Than obtained a transparent bulk solid, it was washed several times with ethanol and water, respectively. After vacuum dried at $60{ }^{\circ} \mathrm{C}, \mathrm{CTF}-1$ was obtained as white powder. CTF-2 was synthesized as the procedure below. Substitute 4,4'-biphenyldicarbonitrile (4 mmol, J\&K Chemical) for 1,4-dicyanobenzene with the synthesis method of CTF-1 described above, and the yellow CTF-2 solid powders were obtained. CTF-m was synthesized as the procedure below. Mix 1,4-dicyanobenzene (2 mmol) with 4,4'-biphenyldicarbonitrile ( $2 \mathrm{mmol}$ ), and use the method described above, then the yellow CTF-m solid powders were obtained. CTF-mi was synthesized as the procedure below. $3.32 \mathrm{~g} \mathrm{ZnCl}_{2}, 2 \mathrm{mmol}$ 1,4-dicyanobenzene and $2 \mathrm{mmol}$ 4,4'-biphenyldicarbonitrile were transferred in an pyrex ampoule under an inert atmosphere, sealed and heated to $400{ }^{\circ} \mathrm{C}$ for $4 \mathrm{~h}$ and kept at this temperature for $40 \mathrm{~h}$. After the ampoule was cooled down to room temperature, the reaction mixture was stirred subsequently in water and $1 \mathrm{~mol} / \mathrm{L} \mathrm{HCl}$ at room temperature for $24 \mathrm{~h}$ to remove $\mathrm{ZnCl}_{2}$. Afterwards, the resulting black powder was filtered, washed successively with water and THF and dried in vacuum at $120{ }^{\circ} \mathrm{C}$ for further analysis.

Characterization of CTF-1, CTF-2 and CTF-m. Solid State 13C CP magic angle spinning (MAS) nuclear magnetic resonance (NMR) measurements were carried out using Bruker Avance II solid state NMR spectrometer operating at $300 \mathrm{MHz}$ Larmor frequency equipped with a standard $4 \mathrm{~mm}$ MAS double resonance probe head. The 
X-ray photoelectron spectroscopy (XPS) experiments were performed on a Thermo Scientific ESCA-Lab-200i-XL spectrometer (Waltham, MA) with monochromatic Al Al $\alpha$ radiation $(1486.6 \mathrm{eV})$, the $\mathrm{C} 1 \mathrm{~s}$ and $\mathrm{N}$ 1s peak spectra were analyzed using XPS Peak 4.1 software. The Raman spectra were obtained using a Lab Ram HRUV Raman spectrometer (JDbin-yvon, FR); laser excitation was provided by an $\mathrm{Ar}^{+}$laser at a wavelength of $532 \mathrm{~nm}$. The fourier transform infrared spectroscopy (FTIR) spectra were recorded in the 4000-400 $\mathrm{cm}^{-1}$ region with a resolution of $4 \mathrm{~cm}^{-1}$ using a Nicolet Thermo NEXUS 670. The scanning electron microscopy (SEM) was performed through Nano nova 450 SEM (FEI, Netherlands). The transmission electron microscopy (TEM) was performed through Tecnai G2F30 S-Twin TEM (FEI, Netherlands). The Brunauer-Emmett-Teller (BET) was estimated by nitrogen adsorption-desorption at $-196{ }^{\circ} \mathrm{C}$ with a NOVA-2000E surface area analyzer.

The UV-vis DRS studies of all the CTFs were carried out with a Shimadzu UV-2550 UV-vis spectrophotometer in the wavelength range of $200-800 \mathrm{~nm}$ with $\mathrm{BaSO}_{4}$ as the reference for baseline correction. Further, with the help of the Kubelka-Munk Function, the reflectance data were converted into absorption terms. The periodic on/off photocurrent responses, the Electrochemical impedance spectra (EIS) and the Mott-Schottky plot were recorded using a three-electrode quartz cell on a $\mathrm{CHI}$ 660E electrochemical workstation (CH Instrument, USA). For the periodic on/off photocurrent responses, the catalyst dispersed on indium tin oxide (ITO) glass acted as the working electrode, and a Pt flake and $\mathrm{Ag} / \mathrm{AgCl}$ (saturated $\mathrm{KCl}$ ) were used as the counter and reference electrode, respectively. The electrolyte was $0.1 \mathrm{M}$ $\mathrm{Na}_{2} \mathrm{SO}_{4}$ solution, and the light source was a $250 \mathrm{~W}$ xenon high-brightness cold light source (XD-300) equipped with a UV cutoff filter $(\lambda>400 \mathrm{~nm})$. The electrochemical impedance spectra (EIS) was recorded with an alternating current (ac) voltage magnitude of $5 \mathrm{mV}$ over a frequency range of $10^{6}-10^{-2} \mathrm{~Hz}$ in the dark. The Mott-Schottky plot was performed in $0.1 \mathrm{~mol} / \mathrm{L}^{-1} \mathrm{Na}_{2} \mathrm{SO}_{4}(\mathrm{pH}=6.8)$ with frequencies of $1000 \mathrm{~Hz}$. The catalyst dispersed on fluorine-doped tin oxide (FTO) glass acted as the working electrode. The voltage was scanned from the open-circuit $(0.2 \mathrm{~V})$ to 1.0 
$\mathrm{V}$. The position of conduction band was approximately equal to the flat band. So the conduction band was gotten from the Mott-Scottky analysis by the extrapolation Mott-Scottky plot which intersect at X-axis. ${ }^{1}$ The active radical was examined by a Bruker model of electron spin resonance (ESR) employing 5,5-dimethyl-1-pyrroline $\mathrm{N}$-oxide (DMPO) as the spin trapper. Typically, CTFs $(30 \mathrm{mg})$ was added in a $80 \mathrm{mM}$ DMPO solution with aqueous dispersion for DMPO- $\mathrm{OH}$ and methanol dispersion for DMPO- $\cdot \mathrm{O}_{2}^{-}$. without and with irradiation under the Xenon lamp with an AM1.5, $100 \mathrm{~mW} / \mathrm{cm}^{2}$ filter.

The stability of CTF-m was investigated by Thermogravimetric analyse (TGA), X-ray diffraction (XRD), XPS and SEM. TGA of CTF-m was carried out in dynamic air atmosphere with a Netzsch Thermo-Microbalance Apparatus TG 209 F3 Tarsus. XRD of CTF-m and CTF-m after regeneration was examined using a Thermal ARL $\mathrm{X}$-ray diffractometer (Thermo, France) at room temperature with $\mathrm{Cu} \operatorname{K\alpha }$ radiation $(\lambda=$ $0.15418 \mathrm{~nm}$ ) at a scan rate of $0.01^{\circ} \mathrm{s}^{-1}$ in the $2 \theta$ range from 5 to $60^{\circ}$. XPS and SEM of CTF-m after adsorption of BEN as well as regeneration were examined by the methods described above.

Adsorption Experiments. Benzene (99.5\%+, Aladdin Co. Ltd.), phenol (99.5\%+, Aladdin Co. Ltd.) and naphthalene $(99 \%+, \mathrm{J} \& \mathrm{~K}$ Chemical) were selected as model aromatic pollutants. Batch adsorption experiments were performed in PTFE screw cap vials sealed with tin foil at $25 \pm 1{ }^{\circ} \mathrm{C} ; 60 \mathrm{~mL}$ vials were used for all the $\mathrm{CTFs}$ samples. Each point, either the blank or calibration control, was evaluated in duplicate. CTF-1, CTF-2 or CTF-m was used as an adsorbent in the liquid phase, and the CTF-1, CTF-2 or CTF-m powder was prepared into a background solution containing $0.01 \mathrm{~mol} / \mathrm{L}$ $\mathrm{CaCl}_{2}$ in deionized water with $200 \mathrm{mg} / \mathrm{L} \mathrm{NaN}_{3}$ as a bio-inhibitor followed by ultrasonication to stabilize the dispersed solution.

The adsorption kinetic studies were conducted with an initial BEN, PHE or NAP concentration of $2 \mathrm{mg} / \mathrm{L}(0.0256 \mathrm{mmol} / \mathrm{L}$ for $\mathrm{BEN}, 0.0156 \mathrm{mmol} / \mathrm{L}$ for NAP and 
$0.0213 \mathrm{mmol} / \mathrm{L}$ for PHE). And the solid-to-water ratios for CTF-1, CTF-2 or CTF-m were $1 \mathrm{mg}$ per $50 \mathrm{~mL}$. The remaining concentrations in a series of independent samples were measured from $10 \mathrm{~s}$ to $1800 \mathrm{~s}$. Isotherm experiments were performed with solid-to-water ratios at $1 \mathrm{mg}$ of CTFs samples and $50 \mathrm{~mL}$ of BEN, PHE or NAP solution. The initial concentrations of solutions were controlled to obtain equilibrium concentration ranges $0.5-20 \mathrm{mg} / \mathrm{L}$ for all three pollutants $(0.0064 \mathrm{mmol} / \mathrm{L}-0.256$ $\mathrm{mmol} / \mathrm{L}$ for BEN, $0.0039 \mathrm{mmol} / \mathrm{L}-0.156 \mathrm{mmol} / \mathrm{L}$ for NAP and $0.0053 \mathrm{mmol} / \mathrm{L}-$ $0.2125 \mathrm{mmol} / \mathrm{L}$ for PHE). The vials were placed on a shaker and agitated in the dark at $120 \mathrm{rpm}$ for $4 \mathrm{~h}$. The solution was separated from the solid by filtering with 0.22 $\mu \mathrm{m}$ membrane filters.

Then, $500 \mu \mathrm{L}$ of the supernatants were mixed with $500 \mu \mathrm{L}$ of methanol to determine the BEN, PHE and NAP concentration on an Agilent 1200 HPLC (Agilent Eclipse XDB-C 18 column, $4.6 \mathrm{~mm} \times 250 \mathrm{~mm} \times 5 \mu \mathrm{m}$ ) equipped with a G1321A fluorescence detector. Isocratic elution was performed under the following conditions: $80 \%$ methanol:20\% water (v:v) with a wavelength of $204 \mathrm{~nm}$ for BEN at a flow rate of $1.0 \mathrm{~mL} / \mathrm{min}, 70 \%$ methanol:30\% water (v:v) with a wavelength of $270 \mathrm{~nm}$ for PHE at a flow rate of $1.0 \mathrm{~mL} / \mathrm{min}$, and $90 \%$ methanol:10\% water (v:v) with a wavelength of $219 \mathrm{~nm}$ for NAP at a flow rate of $1.0 \mathrm{~mL} / \mathrm{min}$. The results showed no noticeable mass loss, and the amount of BEN, PHE and NAP adsorbed by the CTFs materials was calculated from the difference between the initial and the equilibrium concentrations.

Influences of Competing Ions and Mixture of Pollutants. The influences of competing ions was studied. $0.5 \mathrm{mg} / \mathrm{L} \mathrm{MgCl}_{2}, \mathrm{CaCl}_{2}$ and $\mathrm{Na}_{3} \mathrm{PO}_{4}$ were added separately into adsorption experiment for BEN, NAP as well as PHE and photocatalytic regeneration experiment for BEN of CTF-m to examine the influence of $\mathrm{Mg}^{2+}, \mathrm{Ca}^{2+}$ and $\mathrm{PO}_{4}{ }^{3-}$, respectively. 
The influence of mixture of pollutants was studied. Isotherm experiments were performed with solid-to-water ratios at $1 \mathrm{mg}$ of CTFs samples and $50 \mathrm{~mL}$ of mixture of BEN, PHE and NAP solution. The initial concentrations of solutions were controlled to obtain equilibrium concentration ranges $0.5-20 \mathrm{mg} / \mathrm{L}$ for all three pollutants $(0.0064 \mathrm{mmol} / \mathrm{L}-0.256 \mathrm{mmol} / \mathrm{L}$ for BEN, $0.0039 \mathrm{mmol} / \mathrm{L}-0.156 \mathrm{mmol} / \mathrm{L}$ for NAP and $0.0053 \mathrm{mmol} / \mathrm{L}-0.2125 \mathrm{mmol} / \mathrm{L}$ for PHE). The vials were placed on a shaker and agitated in the dark at $120 \mathrm{rpm}$ for $4 \mathrm{~h}$. The solution was separated from the solid by filtering with $0.22 \mu \mathrm{m}$ membrane filters.

Kinetic Models. The pseudo first-order model can be presented as: $\ln \left(q_{\mathrm{e}}-q_{\mathrm{t}}\right)=\ln q_{\mathrm{e}}-$ $k_{1} t(1)$,

where $k 1$ is the rate constant of the pseudo first-order model of adsorption $(1 / \mathrm{h})$; $q_{\mathrm{e}}$ and $q_{\mathrm{t}}$ is the absorbed amount of naphthalene at equilibrium and at different time (mg/g), respectively. The values of $k_{1}$ and $q_{\mathrm{e}}$ can be determined from the slope and intercept of linear fittings of $\ln \left(q_{\mathrm{e}}-q_{\mathrm{t}}\right)$ versus $t$.

The pseudo second-order model is given by:

$$
\mathrm{t} / q_{\mathrm{t}}=1 / k_{2} q_{\mathrm{e}}^{2}+t / q_{\mathrm{e}}(2)
$$

where $k 2$ is the rate constant of the pseudo second-order model of adsorption $(\mathrm{g} /(\mathrm{mg} \cdot \mathrm{h}))$, while $q_{\mathrm{e}}$ and $q_{\mathrm{t}}$ are defined the same as the parameters in the pseudo first-order model. The values of $k_{2}$ and $q_{\mathrm{e}}$ can be determined from the slope and intercept of linear fittings of $t / q_{\mathrm{t}}$ versus $t$.

Adsorption Models. The Langmuir and Freundlich models were utilized to fit the adsorption isotherms.

The following expression describes the Langmuir equation: 


$$
q_{\mathrm{e}}=q_{\mathrm{m}} C_{\mathrm{e}} /\left(K_{\mathrm{L}}+C_{\mathrm{e}}\right)(3)
$$

where $q_{\mathrm{e}}(\mathrm{mg} / \mathrm{g})$ is the equilibrium-sorbed concentration, $C_{\mathrm{e}}(\mathrm{mg} / \mathrm{L})$ is the equilibrium solution phase concentration, $K_{\mathrm{L}}(\mathrm{L} / \mathrm{g})$ is the Langmuir constant, and $q_{\mathrm{m}}$ $(\mathrm{mg} / \mathrm{g})$ represents the maximum adsorption capacity of the adsorbent.

The following expression describes the Freundlich equation:

$$
q_{\mathrm{e}}=K_{\mathrm{f}} C_{\mathrm{e}} N(4)
$$

where $K_{\mathrm{f}}[(\mathrm{mg} / \mathrm{g}) /(\mathrm{mg} / \mathrm{L}) \mathrm{N}]$ is the Freundlich affinity coefficient, and $N$ is the exponential coefficient.

Percentage Regenerated. The percentage regenerated can be presented as:

$$
R=q_{\mathrm{n}+1} / q_{\mathrm{n}}(5)
$$

where $R$ means the percentage regenerated of the adsorption capacity, $q_{\mathrm{n}}$ is adsorption capacity in cycle $n$.

Computational Details. The interaction mechanism of aromatic compounds with CTFs was demonstrated by using the B3LYP hybrid functional of density functional theory (DFT) with the 6-31G (d) basis set. ${ }^{2}$ The dispersion forces and solvation effects were corrected by the empirical formula of Grimme ${ }^{3-5}$ and a conductor-like polarizable continuum model $(\mathrm{CPCM}){ }^{6-8}$ respectively. The nature of local minima was confirmed by analytical calculations of the Hessian by frequency calculations performed at the same level of theory as in the optimizations. All calculations were carried out with the Gaussian 09 software package. ${ }^{9}$ 


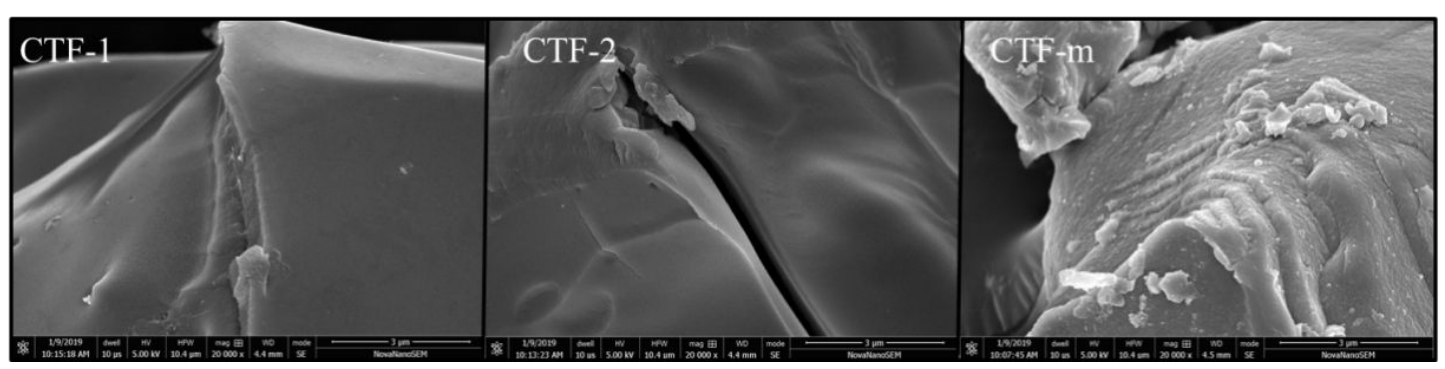

Figure S-1. SEM of CTF-1, CTF-2 and CTF-m. 


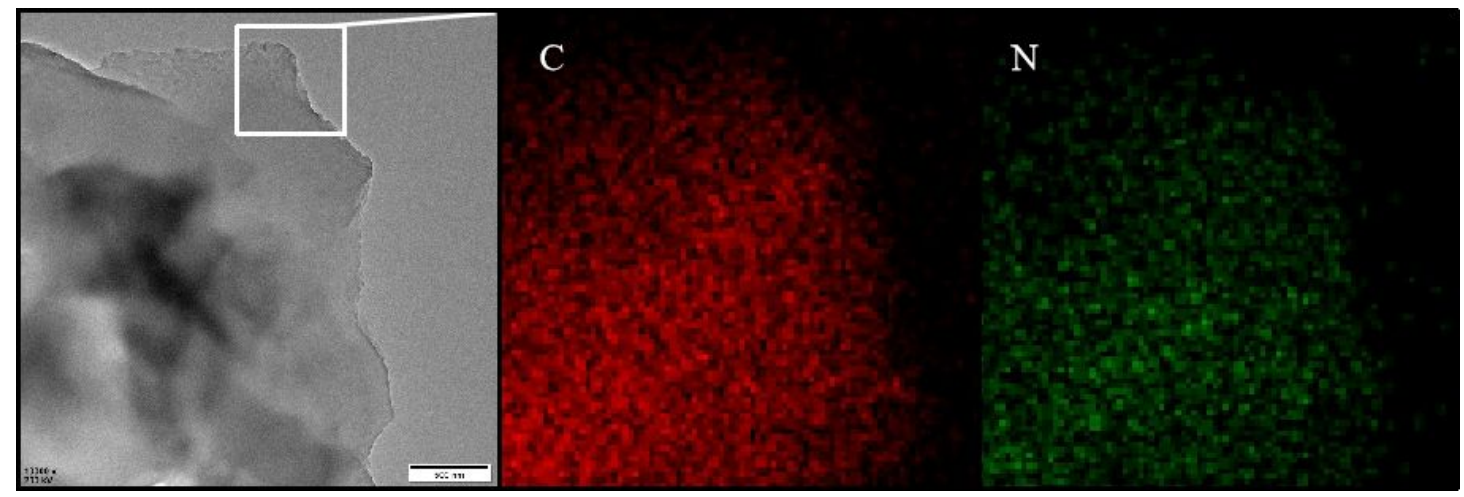

Figure S-2. TEM and elemental mapping of CTF-1, CTF-2 and CTF-m. 


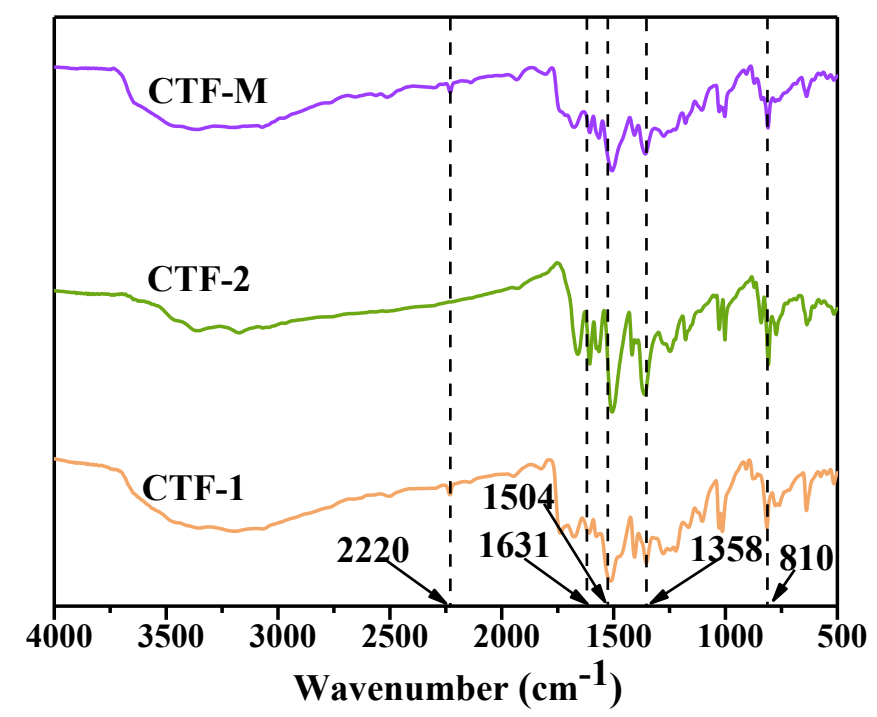

Figure S-3. FTIR spectra of CTF-1, CTF-2 and CTF-m.

The absorption band had two distinct absorption peaks in the position of 1504 and $1358 \mathrm{~cm}^{-1}$, which were related to $\mathrm{C}-\mathrm{N}$ stretching and breathing patterns in triazine rings, respectively. ${ }^{10}$ And the signal at $2220 \mathrm{~cm}^{-1}$ which was the typical signal of the terminal nitrile group disappeared almost in the structure of CTFs. ${ }^{11}$ The results supported that most of the nitrile groups transformed to triazine rings in CTFs. And the absorption peaks at 1631 and $810 \mathrm{~cm}^{-1}$ were corresponding to the benzene rings in the CTFs unit. The results above confirmed that the triazine rings and benzene rings were present in CTFs. 


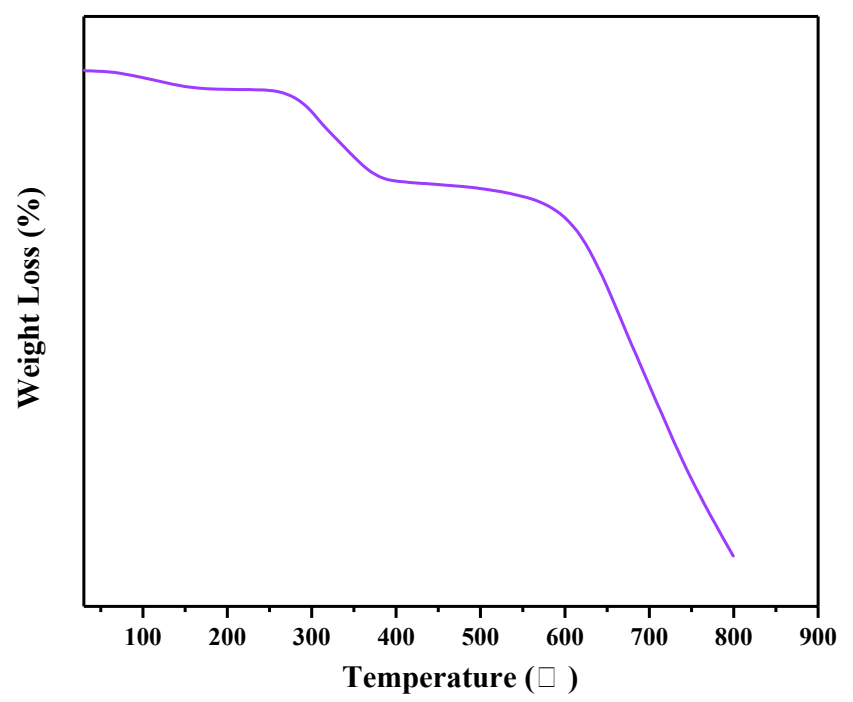

Figure S-4. TGA curve of CTF-m.

The TGA curve showed that CTF-m was thermally stable up to $270{ }^{\circ} \mathrm{C}$ under an air atmosphere 


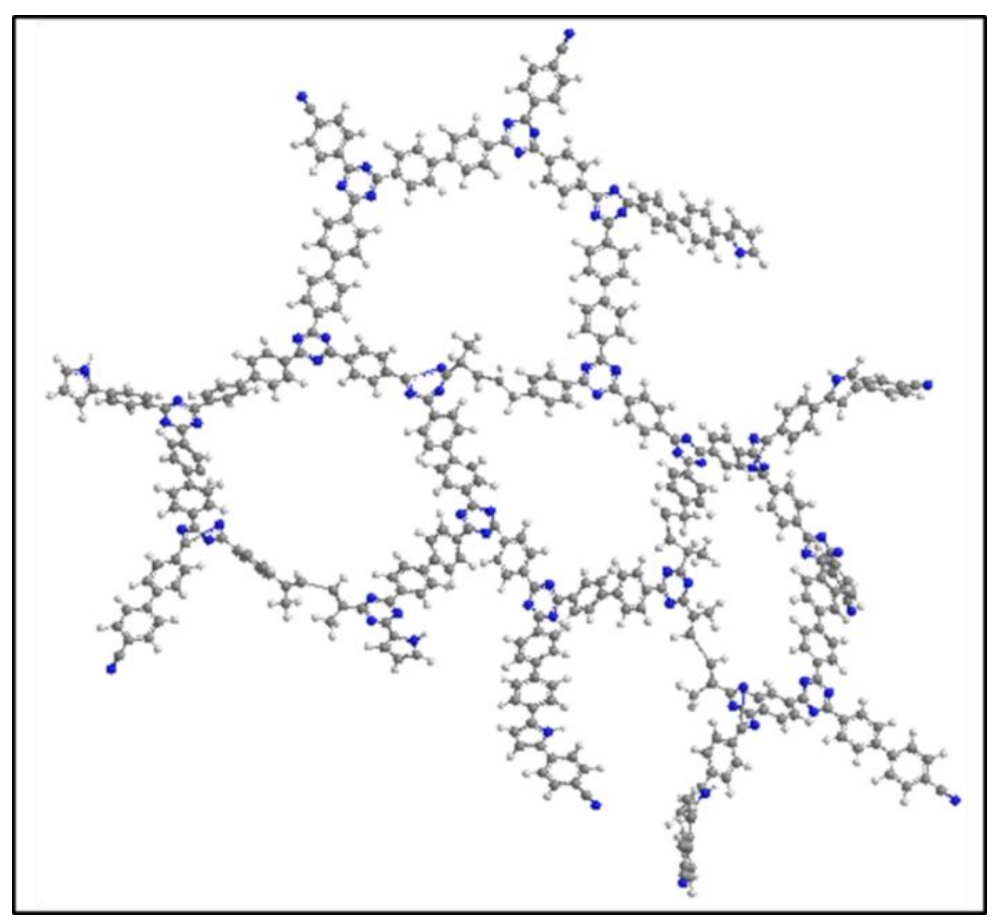

Figure S-5. Molecular structure of CTF-m 

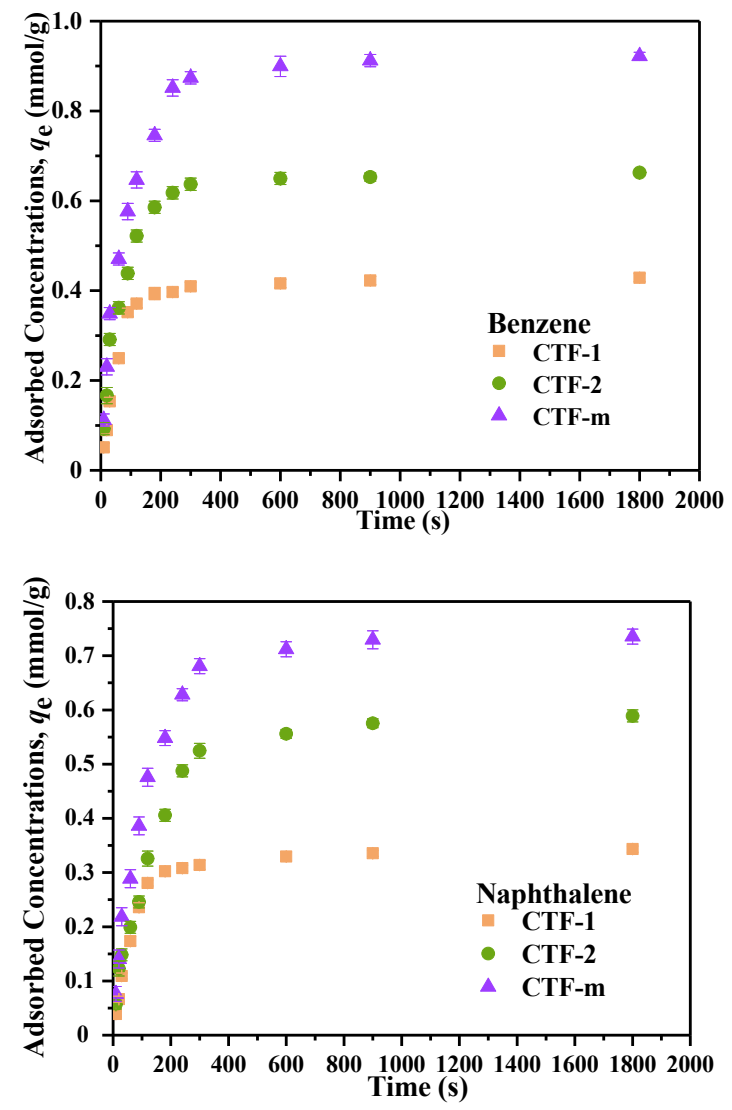


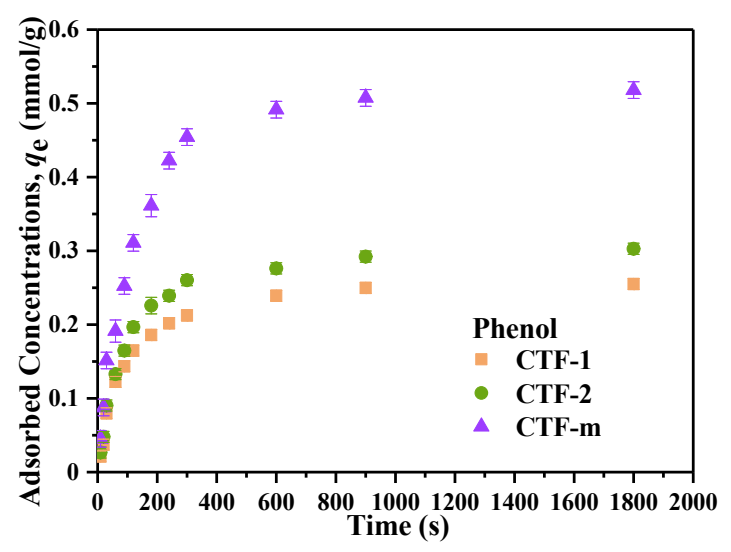

Figure S-6. Adsorption kinetics of BEN, NAP and PHE onto CTF-1, CTF-2, and CTF-m. 


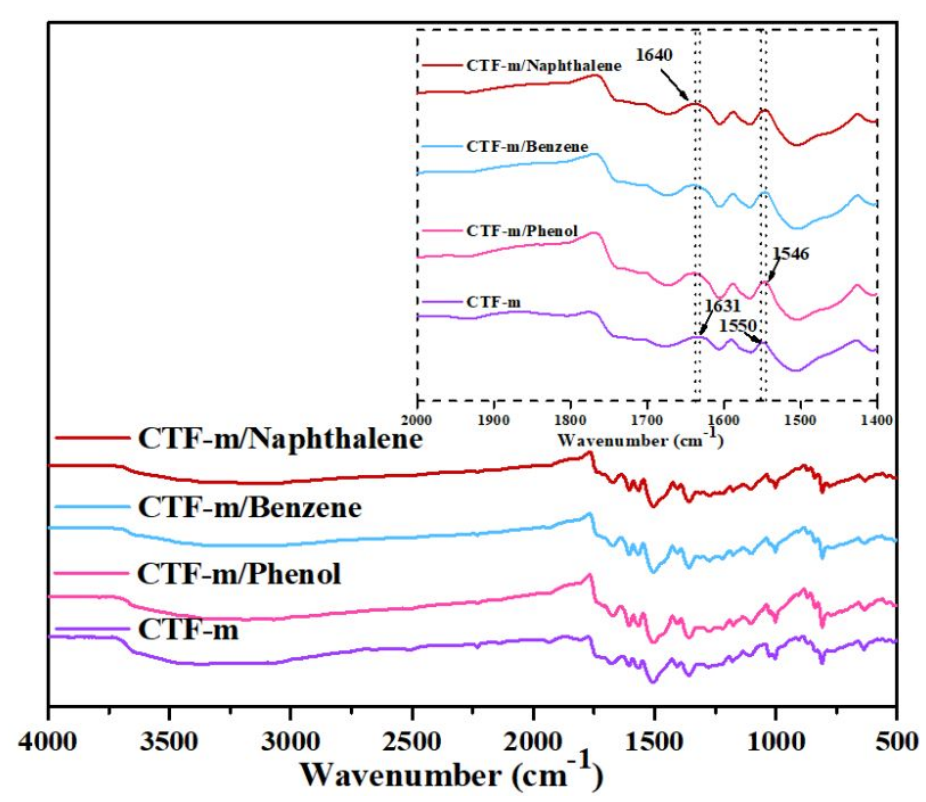

Figure S-7. FTIR of CTF-m before and after adsorption. 
The changes in crystal structure, surface composition and morphology of CTF-m before and after used were insignificant, demonstrating its good stability.

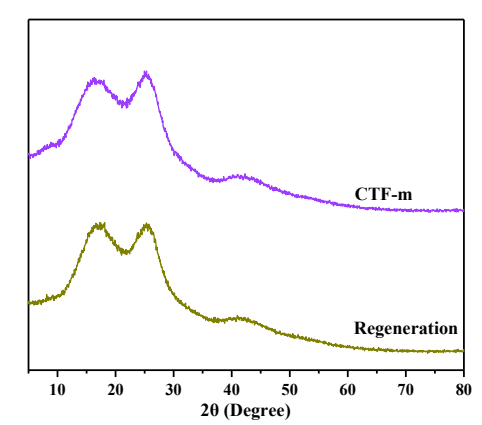

Figure S-8. XRD of original CTF-m and CTF-m after regeneration.

From the XRD spectra, the two main peaks at $16^{\circ}$ and $25^{\circ}$, were characteristics of the (100) facet corresponding to in-plane reflection and the (001) plane arising from the vertical spacing between stacked sheets, ${ }^{14}$ respectively, of CTF-m after regeneration maintained well.

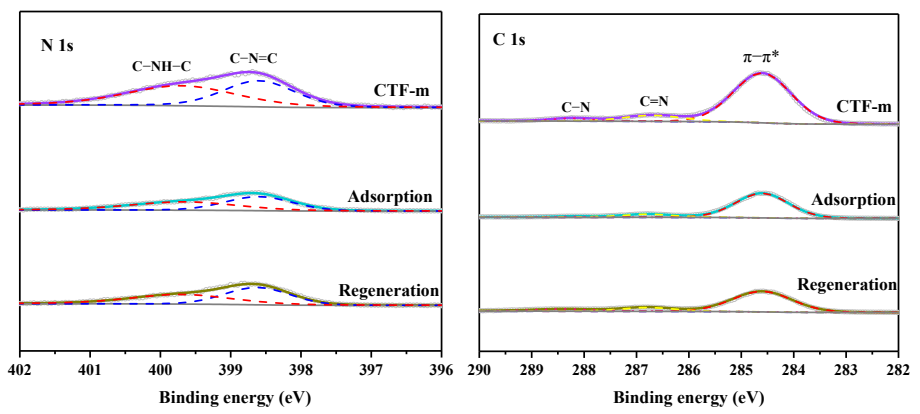


Figure S-9. XPS spectra of original CTF-m and CTF-m after adsorption of BEN as well as regeneration. (The content of chemical bonds are presented in Table S-6)

In the case of XPS peak-differentiating, the proportion of each chemical bond in CTF-m after regeneration was almost unchanged compared with original CTF-m.

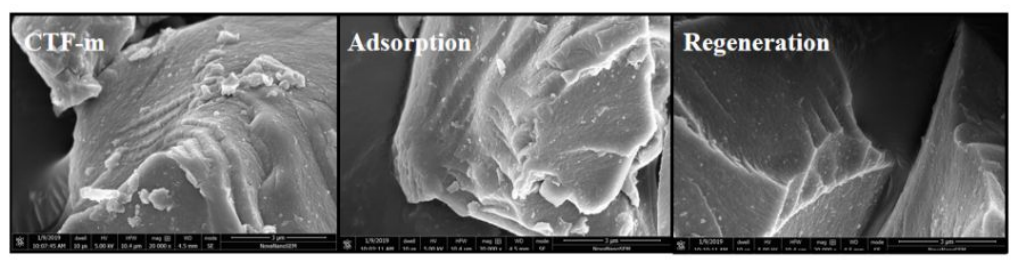

Figure S-10. SEM of original CTF-m and CTF-m after adsorption of BEN as well as regeneration.

As to the SEM image of CTF-m after regenerated, its morphology seemed to be unaltered compared with original CTF-m.

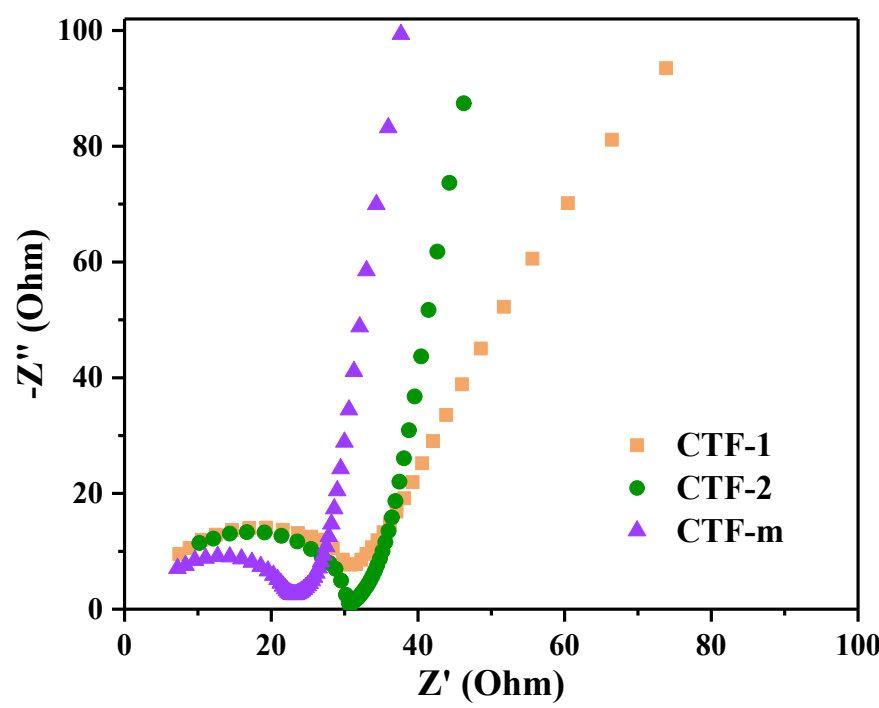

Figure S-11. The resistance of charge transfer (RCT) recorded by EIS in the dark of CTF-1, CTF-2 and CTF-m. 


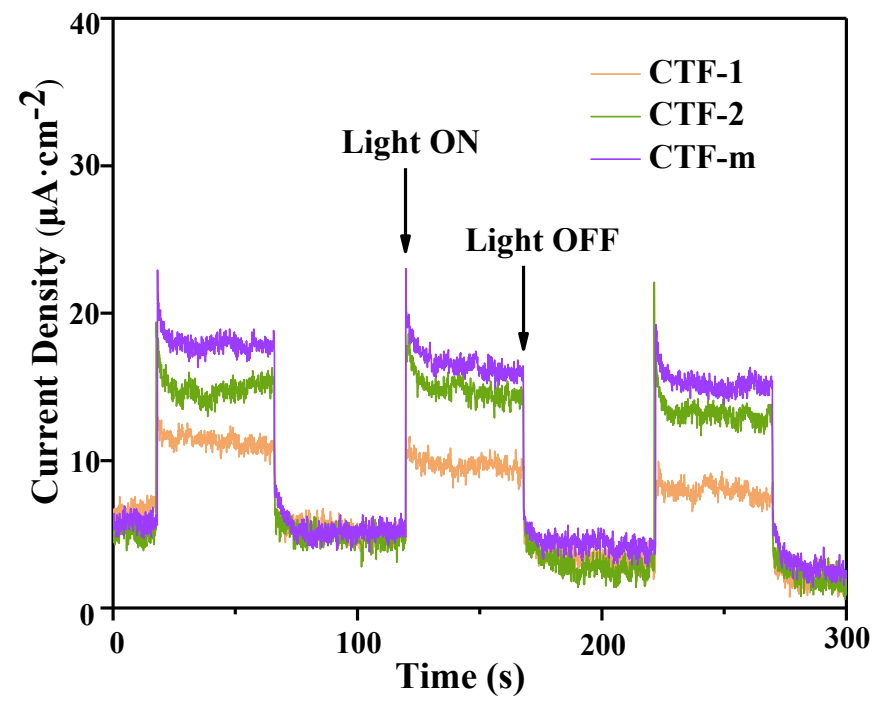

Figure S-12. Periodic on/off photocurrent responses of CTF-1, CTF-2 and CTF-m at 1.2 V vs Reversible Hydrogen Electrode (RHE) under visible-light irradiation. 


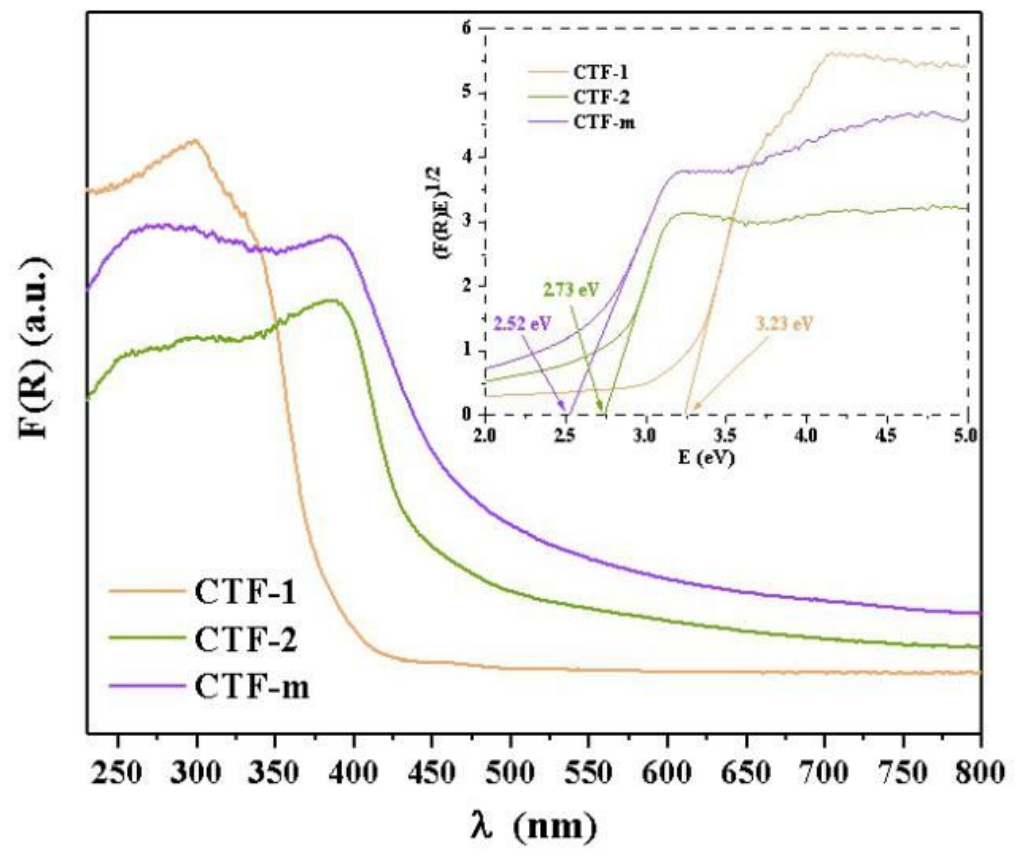


Figure S-13. UV/Vis diffuse reflection spectra and Kubelka-Munk of CTF-1, CTF-2 and CTF-m. 


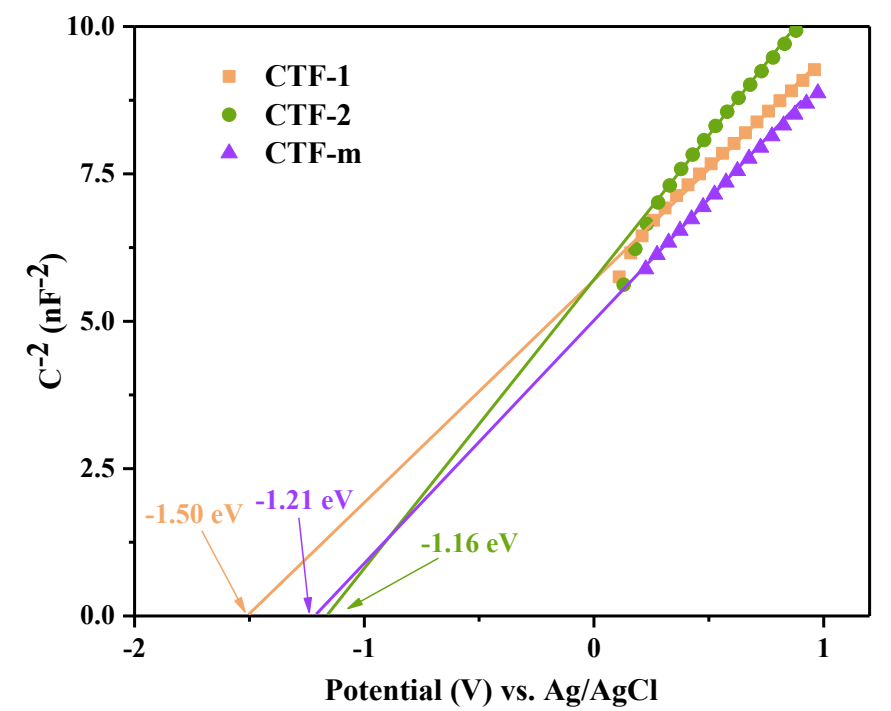

Figure S-14. The typical Mott-Schottky plots (scatters) and simulation (lines) of CTF-1, CTF-2 and CTF-m. 


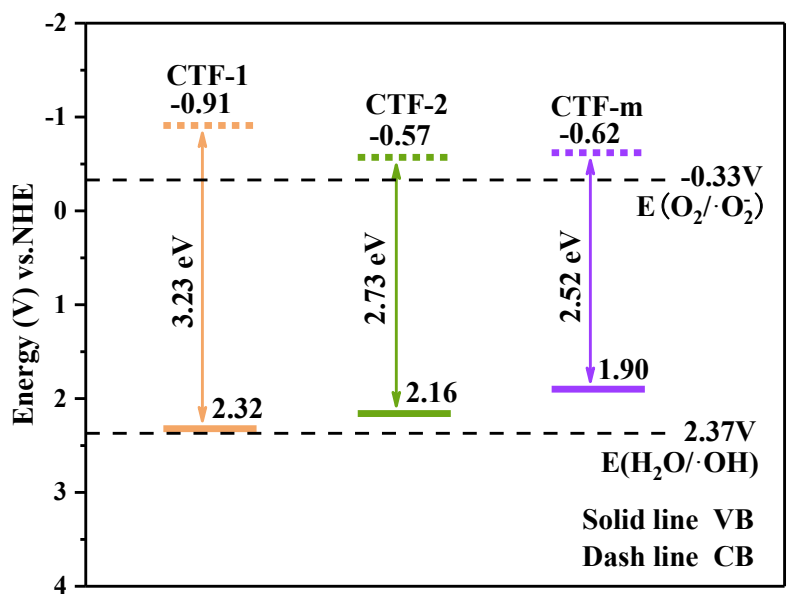

Figure S-15. CTFs energy band structure ( $E_{\mathrm{CB}}$ vs. NHE was calculated from $E_{\mathrm{CB}}$ vs. $\mathrm{Ag} / \mathrm{AgCl})$. 


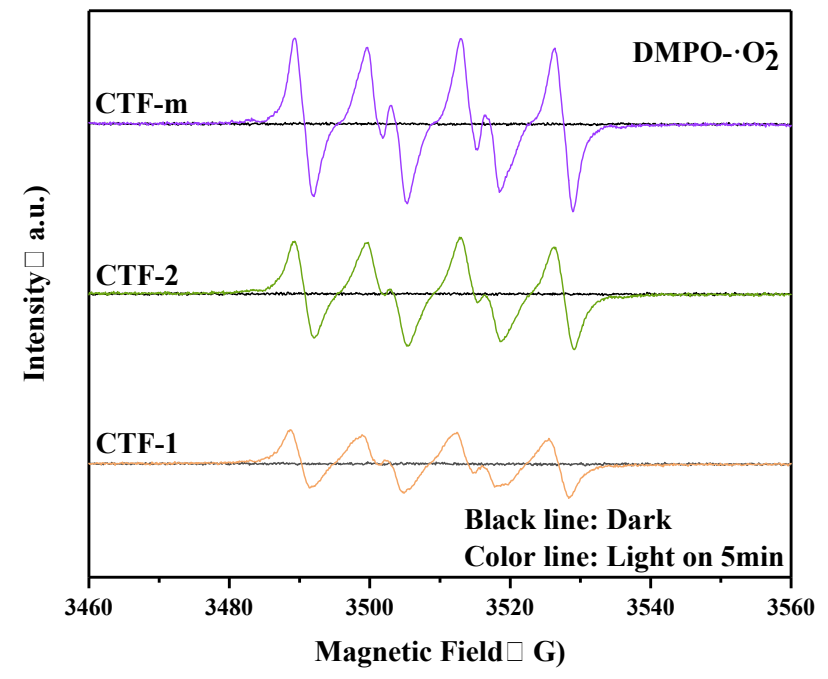

Figure S-16. DMPO spin-trapping ESR spectra of CTFs in methanol dispersion for $\mathrm{DMPO}-\mathrm{O}_{2}^{-}$. 


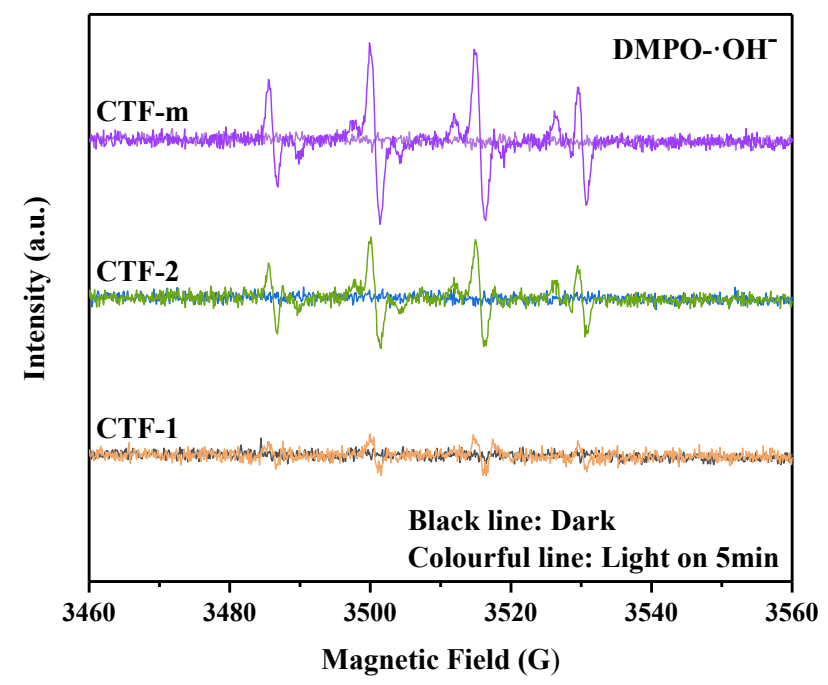

Figure S-17. DMPO spin-trapping ESR spectra of CTFs in aqueous dispersion for DMPO-·OH. 


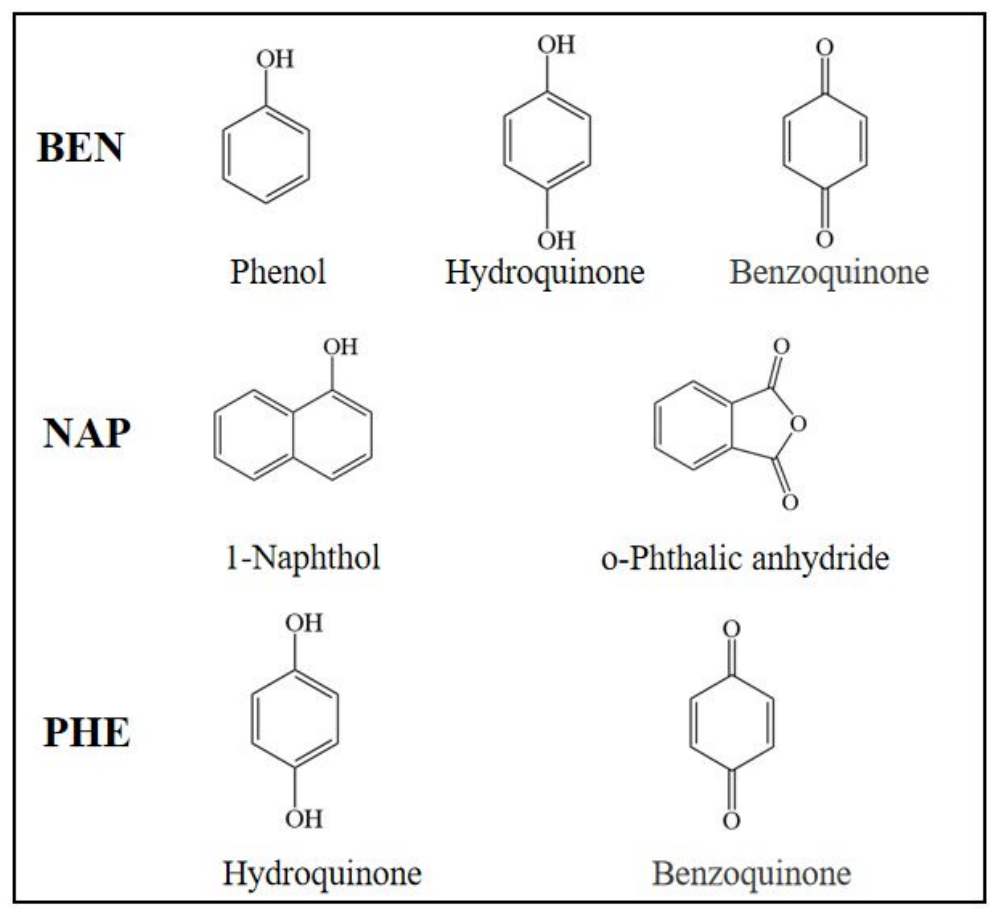

Figure S-18. Intermediates detected by HPLC in the photocatalytic regeneration of CTF-m adsorbed BEN, NAP and PHE, respectively.

The intermediates of adsorbed pollutants during the photocatalytic regeneration process were detected, but only marginal related products were detected in the filtrate. 
It was supposed that most of intermediates were adsorbed onto the CTF-m surface. Subsequently, we extracted the intermediates from CTF-m by methanol and analyzed by HPLC. The results showed that intermediates including phenol, hydroquinone and benzoquinone were detected for CTF-m adsorbed benzene, intermediates including 1-naphthol and o-phthalic anhydride were detected for CTF-m adsorbed naphthalene, and intermediates including hydroquinone and benzoquinone were detected for CTF-m adsorbed phenol. These hydroxylation intermediates suggested that the oxidation of adsorbed pollutants during photocatalytic regeneration underwent $\cdot \mathrm{OH}$-attack pathway. ${ }^{12,13}$ Therefore, it was reliable that the adsorbed pollutants were photocatalytically removed from CTF-m.

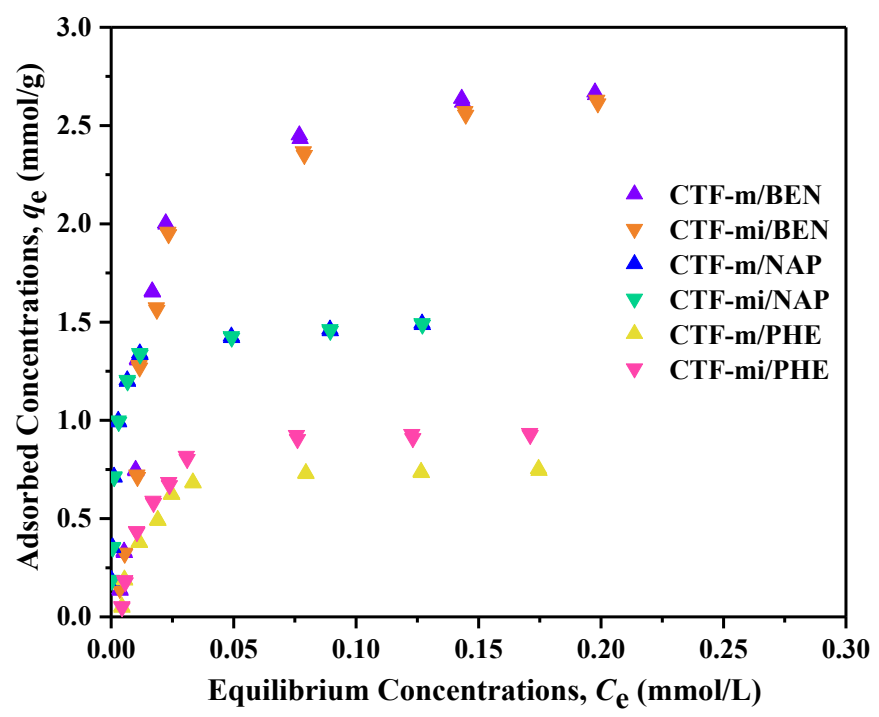

Figure S-19. Adsorption isotherms of BEN, NAP and PHE onto CTF-m and CTF-mi. 


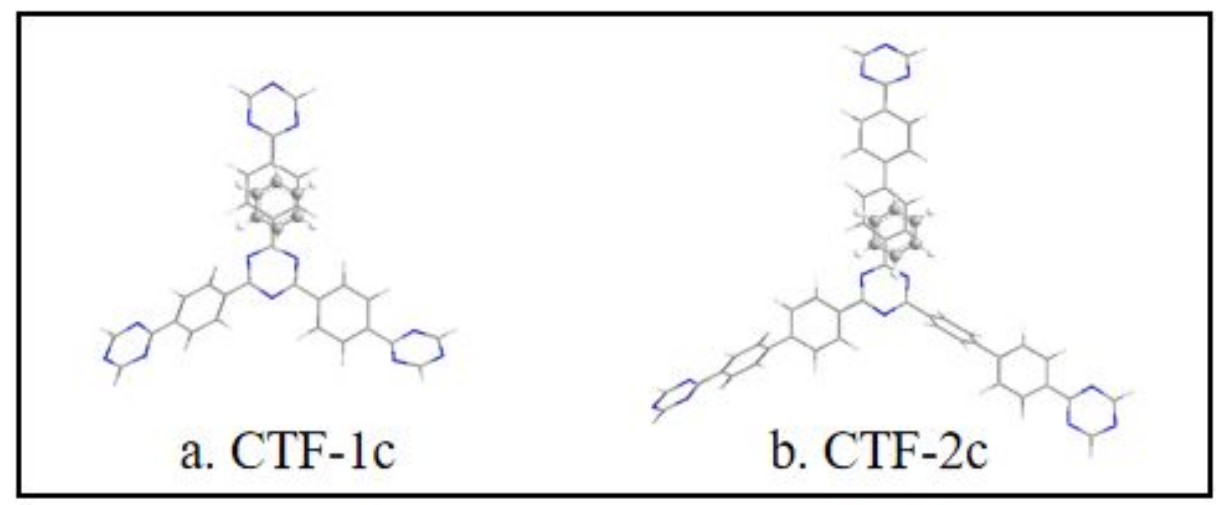

Figure S-20. Top view of the optimized geometrical structures for the adsorption of BEN on CTF-1c (a) and CTF-2c (b). 

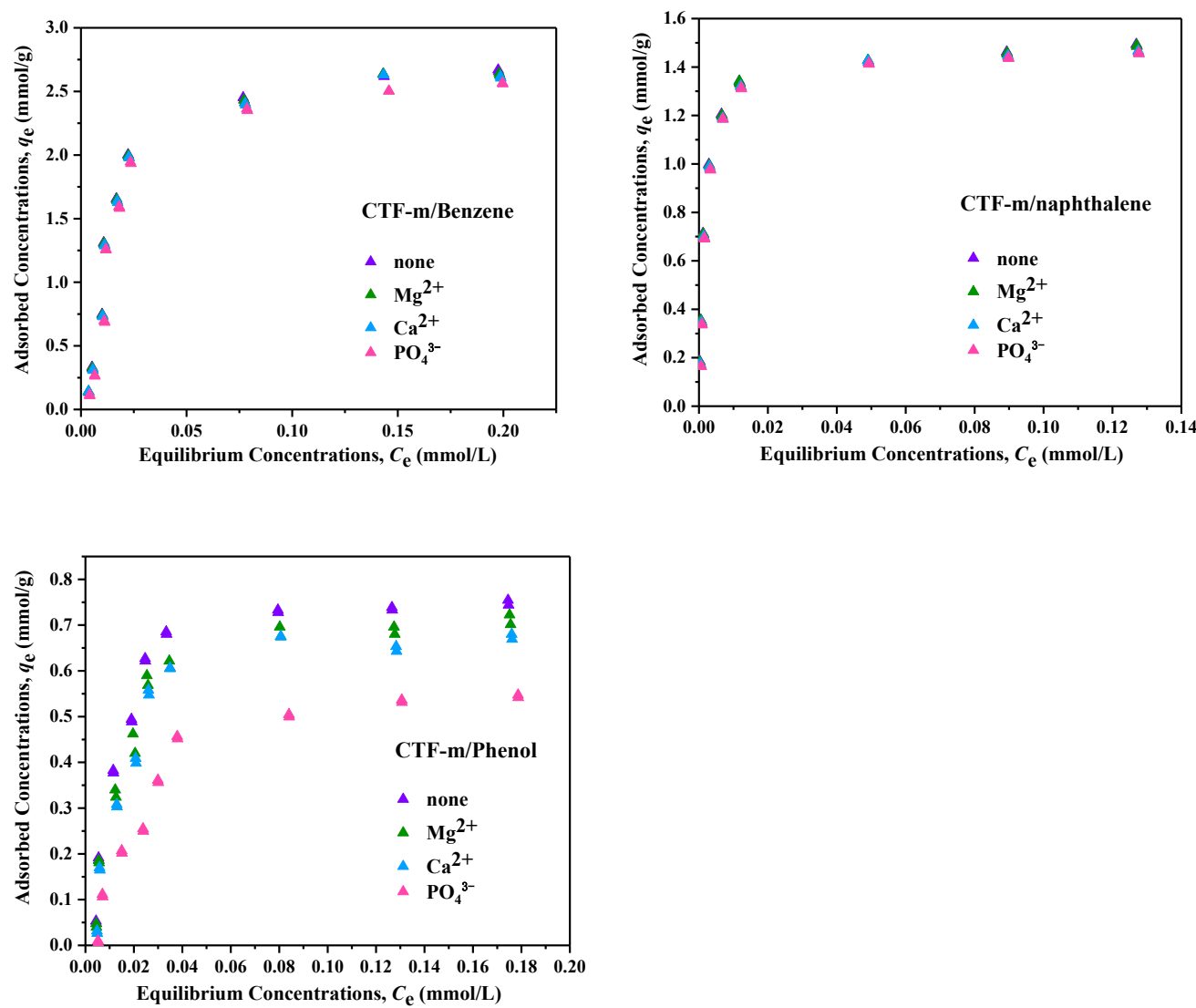

Figure S-21. The influence of competing ions $\mathrm{Mg}^{2+}, \mathrm{Ca}^{2+}$ and $\mathrm{PO}_{4}{ }^{3-}$ on the adsorption of BEN, NAP and PHE onto CTF-m. 


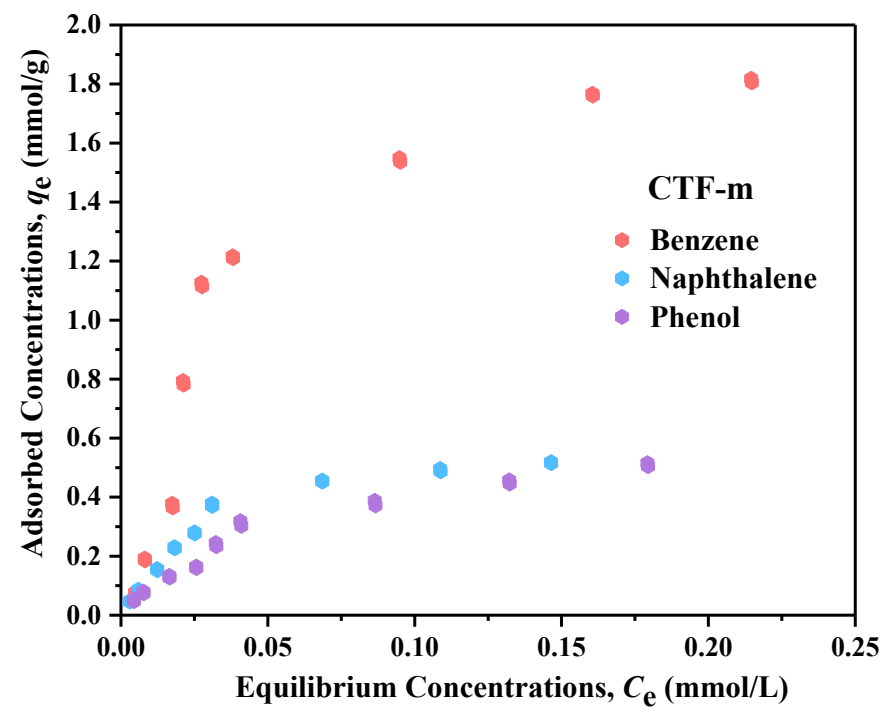

Figure S-22. The influence of mixture of pollutants on the adsorption of CTF-m. 
Table S-1. The Content of Chemical Bonds in CTF-1, CTF-2 and CTF-m Derived from XPS Data.

\begin{tabular}{cccc}
\hline sample & CTF-1 & CTF-2 & CTF-m \\
N 1s & & & \\
C-N=C (triazine nitrogen), \% & 60.82 & 60.34 & 55.29 \\
C-N-C (pyrrolic nitrogen), \% & 39.18 & 39.66 & 44.71 \\
C 1s & & & \\
C=N, \% & 8.227 & 4.958 & 3.598 \\
C-N, \% & 11.14 & 4.065 & 18.64 \\
$\pi-\pi * \%$ & 80.63 & 90.98 & 77.76 \\
\hline
\end{tabular}


Table S-2. Adsorption Kinetic Parameters of Benzene (BEN), Naphthalene (NAP) and Phenol (PHE) onto CTF-1, CTF-2 and CTF-m. ${ }^{\text {a) }}$

\begin{tabular}{|c|c|c|c|c|c|c|c|}
\hline \multirow[b]{2}{*}{ pollutant } & \multirow[b]{2}{*}{ adsorbent } & \multicolumn{3}{|c|}{ pseudo first-order } & \multicolumn{3}{|c|}{ pseudo second-order } \\
\hline & & $\begin{array}{c}q_{\mathrm{e}} \\
(\mathrm{mmol} / \mathrm{g})\end{array}$ & $\begin{array}{c}k_{1} \\
(1 / s)\end{array}$ & $R^{2}$ & $\begin{array}{c}q_{\mathrm{e}} \\
(\mathrm{mmol} / \mathrm{g})\end{array}$ & $\begin{array}{c}k_{2} \\
(\mathrm{~g} /(\mathrm{mmol} \cdot \mathrm{s}))\end{array}$ & $R^{2}$ \\
\hline \multirow[t]{3}{*}{ BEN } & CTF-1 & 0.421 & 0.0120 & 0.986 & 0.465 & 0.0172 & 0.989 \\
\hline & CTF-2 & 0.656 & 0.0138 & 0.988 & 0.688 & 0.0207 & 0.953 \\
\hline & CTF-m & 0.904 & 0.0159 & 0.988 & 0.977 & 0.0221 & 0.983 \\
\hline NAP & CTF-1 & 0.334 & 0.00723 & 0.994 & 0.370 & 0.00889 & 0.973 \\
\hline
\end{tabular}




\begin{tabular}{|c|c|c|c|c|c|c|c|}
\hline & CTF-2 & 0.575 & 0.00875 & 0.990 & 0.654 & 0.0117 & 0.985 \\
\hline & CTF-m & 0.723 & 0.0131 & 0.993 & 0.812 & 0.0168 & 0.986 \\
\hline \multirow[t]{3}{*}{ PHE } & CTF-1 & 0.240 & 0.00804 & 0.977 & 0.270 & 0.0103 & 0.993 \\
\hline & CTF-2 & 0.285 & 0.00975 & 0.987 & 0.320 & 0.0121 & 0.995 \\
\hline & CTF-m & 0.503 & 0.00996 & 0.990 & 0.566 & 0.0124 & 0.991 \\
\hline
\end{tabular}

a) The solid solution ratio was $1 \mathrm{mg} / 50 \mathrm{~mL}$. The initial concentrations of BEN, NAP and PHE were 0.0256 $\mathrm{mmol} / \mathrm{L}, 0.0156 \mathrm{mmol} / \mathrm{L}$ and $0.0213 \mathrm{mmol} / \mathrm{L}$, respectively.

Table S-3. The Determined $K_{\mathrm{d}} / K_{\mathrm{HW}}$ Ratio of BEN and NAP onto CTF-1, CTF-2 and CTF-m. ${ }^{\text {a) }}$ 


$\begin{array}{llll}K_{\mathrm{d}} / K_{\mathrm{HW}} \text { of BEN } & 233.471 & 311.605 & 849.535 \\ K_{\mathrm{d}} / K_{\mathrm{HW}} \text { of NAP } & 24.199 & 64.763 & 266.025\end{array}$

a) $K_{\mathrm{HW}}$ is the hexadecane-water partition coefficient. The $\log K_{\mathrm{HW}}$ of BEN and NAP are 2.15 and 3.33, respectively. $K_{\mathrm{d}} / K_{\mathrm{HW}}$ is the normalized distribution coefficient at a certain equilibrium concentration that $K_{\mathrm{d}}$ got the maximum value. 
Table S-4. The Percentage Regenerated of Adsorption Capacity for CTF-1, CTF-2 and CTF-m in the $2^{\text {nd }}$ Cycle of Photocatalytic Regeneration.

\begin{tabular}{llll}
\hline & & Recovery $(\%)$ & \\
sample & CTF-1 & CTF-2 & CTF-m \\
BEN & 92.011 & & 98.039 \\
NAP & 91.489 & 93.103 & 98.780 \\
PHE & 87.501 & 97.222 & 97.143 \\
\hline
\end{tabular}


Table S-5. The Percentage Regenerated of BEN Adsorption Capacity for CTF-m in the $1^{\text {st }}, 2^{\text {nd }}, 3^{\text {rd }}$ and $4^{\text {th }}$ Cycle of Photocatalytic Regeneration.

\begin{tabular}{|c|c|c|c|c|}
\hline \multicolumn{5}{|c|}{ Recovery (\%) } \\
\hline \multirow[t]{2}{*}{ CTF-m/BEN } & $1^{\mathrm{st}}$ & $2^{\text {nd }}$ & $3^{\text {rd }}$ & $4^{\text {th }}$ \\
\hline & 100 & 98.039 & 94.989 & 90.559 \\
\hline
\end{tabular}


Table S-6. The Content of Chemical Bonds in Original CTF-m and CTF-m after Adsorption of BEN and Regeneration Derived from XPS Data.

\begin{tabular}{cccc}
\hline Sample & CTF-m & Adsorption & Regeneration \\
N 1s & & & \\
C-N=C (triazine nitrogen), $\%$ & 55.29 & 50.94 & \\
C-N-C (pyrrolic nitrogen), $\%$ & 44.71 & 49.06 & 44.62 \\
\hline
\end{tabular}



C 1s
$\mathrm{C}=\mathrm{N}, \%$
3.598
2.135
3.579
$\mathrm{C}-\mathrm{N}, \%$
18.64
13.03
18.57
$\pi-\pi^{*}, \%$
77.76
84.83
77.84

The surface composition of CTF-m after adsorption of BEN changed a certain extent because the commixture of BEN molecules. The increasing $\pi-\pi^{*}$ proportion was derived from the adsorbed BEN molecules. After regeneration, the proportion of each chemical bonds was almost unchanged compared with original CTF-m. 
Table S-7. Surface Area and Pore Characteristics of CTF-1, CTF-2 and CTF-m (Original Sample, after Adsorption and Regeneration).

\begin{tabular}{|c|c|c|c|c|}
\hline Sample & $\mathrm{S}_{\mathrm{BET}^{\mathrm{a}}}\left(\mathrm{m}^{2} / \mathrm{g}\right)$ & $\mathrm{V}_{\text {micro }}{ }^{\mathrm{b})}\left(\mathrm{m}^{3} / \mathrm{g}\right)$ & $\mathrm{V}_{\text {total }}{ }^{\mathrm{c}}\left(\mathrm{m}^{3} / \mathrm{g}\right)$ & $\mathrm{V}_{\text {micro }} / \mathrm{V}_{\text {total }}(\%)$ \\
\hline CTF-1 & 22 & 0.041 & 0.059 & 69.49 \\
\hline CTF-2 & 37 & 0.031 & 0.071 & 43.66 \\
\hline CTF-m & 43 & 0.025 & 0.079 & 31.65 \\
\hline \multicolumn{5}{|l|}{ CTF-m } \\
\hline & 27 & 0.022 & 0.077 & 28.57 \\
\hline \multicolumn{5}{|l|}{ (after adsorption of BEN) } \\
\hline \multicolumn{5}{|l|}{ CTF-m } \\
\hline & 29 & 0.023 & 0.075 & 30.67 \\
\hline \multicolumn{5}{|l|}{ (after adsorption of NAP) } \\
\hline \multicolumn{5}{|l|}{ CTF-m } \\
\hline & 31 & 0.023 & 0.074 & 31.08 \\
\hline \multicolumn{5}{|l|}{ (after adsorption of PHE) } \\
\hline \multicolumn{5}{|l|}{ CTF-m } \\
\hline (after regeneration from & 42 & 0.024 & 0.079 & 30.38 \\
\hline \multicolumn{5}{|l|}{ BEN) } \\
\hline \multicolumn{5}{|l|}{ CTF-m } \\
\hline (after regeneration from & 41 & 0.024 & 0.078 & 30.77 \\
\hline \multicolumn{5}{|l|}{ NAP) } \\
\hline \multicolumn{5}{|l|}{ CTF-m } \\
\hline & 42 & 0.025 & 0.078 & 32.05 \\
\hline
\end{tabular}

a) $\mathrm{S}_{\mathrm{BET}}$ is the BET specific surface area. b) $\mathrm{V}_{\text {micro }}$ is the pore volume determined by $\mathrm{N}_{2}$ adsorption isotherm using t-plot method. c) $\mathrm{V}_{\text {total }}$ is the total pore volume determined by using the adsorption branch of $\mathrm{N}_{2}$ isotherm at $\mathrm{P} / \mathrm{P}_{0}=$ 0.95 . 
About $30 \%$ of CTF-m surface area decreased while about $90 \%$ of micropores maintained after adsorption, which reflected that only a few pollutants entered into the micropores, providing a supportive evidence for that the outer surface of CTF-m should be regarded as the main adsorption surface. However, the surface areas of CTF-m became to be $42,41,42 \mathrm{~m}^{2} / \mathrm{g}$ after the regeneration process, which meant about $95 \%-98 \%$ of surface area of CTF-m remained after regeneration.

Table S-8. Adsorption Capacity of Benzene (BEN), Naphthalene (NAP) and Phenol (PHE) onto CTF-1, CTF-2 and CTF-m Standardized by Unit Surface Area.

\begin{tabular}{lccc}
\hline & & Samples $\left(\mathrm{mmol} / \mathrm{m}^{2}\right)$ & \\
Pollutant & CTF-1 & CTF-2 & CTF-m \\
BEN & 0.0970 & 0.0691 & 0.0704 \\
NAP & 0.0495 & 0.0347 & 0.0347 \\
PHE & 0.0315 & & 0.0200 \\
\hline
\end{tabular}

To see if the adsorption mainly (or even only) occurred on the outer surface area, we first standardized the adsorption capabilities of CTFs by unit surface area to investigate the influence of surface area on adsorption. Owing to the highest ratio of defects (as high energy adsorption sites), CTF-m should have the most adsorption sites even standardized by unit area. However, one can see that CTF-m just exhibited the medium values among CTFs for all pollutants, which indicated that adsorption may not occur on the whole surface area. Moreover, about $30 \%$ of CTF-m surface area decreased while about $90 \%$ of micropores maintained after adsorption (Table S-7), which reflected that only a few pollutants entered into the micropores, providing supportive evidence for the point that the outer surface of CTF-m should be regarded as the main adsorption surface. 
Table S-9. Regression Parameters of Adsorption Isotherms of Benzene (BEN), Naphthalene (NAP) and Phenol (PHE) onto CTF-m and CTF-mi Fitted by the Freundlich and Langmuir Models.

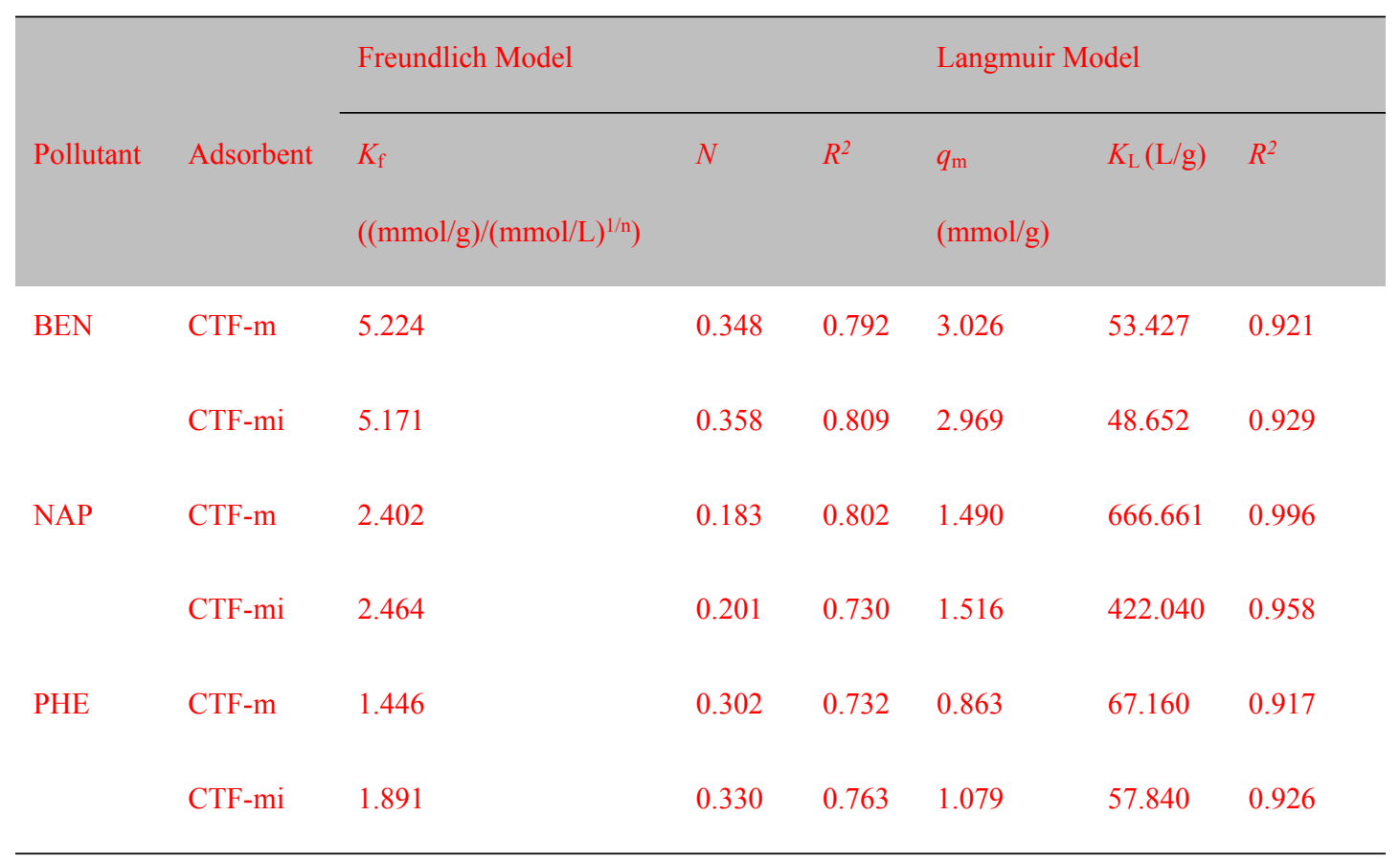

It was found that the adsorption capacities of CTF-mi for BEN, NAP and PHE were very close to those of CTF-m, although the specific surface area of CTF-mi (863 $\mathrm{m}^{2} / \mathrm{g}$ ) was $\sim 20$ times higher than that of CTF-m. Moreover, it further indicated that the surface area was not the determining factor for adsorption ability of CTFs. 
Table S-10. Influence of Competing Ions on Adsorption Isotherms of Benzene (BEN), Naphthalene (NAP) and Phenol (PHE) onto CTF-m Fitted by the Freundlich and Langmuir Models.

\begin{tabular}{|c|c|c|c|c|c|c|c|}
\hline & & Freundlich Model & & & Langmuir & lodel & \\
\hline Pollutant & $\begin{array}{l}\text { Competing } \\
\text { ions }\end{array}$ & $\begin{array}{l}K_{\mathrm{f}} \\
\left((\mathrm{mmol} / \mathrm{g}) /(\mathrm{mmol} / \mathrm{L})^{1 / \mathrm{n}}\right)\end{array}$ & $N$ & $R^{2}$ & $\begin{array}{l}q_{\mathrm{m}} \\
(\mathrm{mmol} / \mathrm{g})\end{array}$ & $K_{\mathrm{L}}(\mathrm{L} / \mathrm{g})$ & $R^{2}$ \\
\hline \multirow[t]{4}{*}{ BEN } & None & 5.224 & 0.348 & 0.792 & 3.026 & 53.427 & 0.921 \\
\hline & $\mathrm{Mg}^{2+}$ & 5.207 & 0.347 & 0.791 & 3.018 & 53.268 & 0.920 \\
\hline & $\mathrm{Ca}^{2+}$ & 5.190 & 0.350 & 0.790 & 3.005 & 51.906 & 0.919 \\
\hline & $\mathrm{PO}_{4}{ }^{3-}$ & 5.116 & 0.360 & 0.772 & 2.953 & 47.019 & 0.899 \\
\hline \multirow[t]{4}{*}{ NAP } & None & 2.402 & 0.183 & 0.802 & 1.490 & 666.661 & 0.996 \\
\hline & $\mathrm{Mg}^{2+}$ & 2.409 & 0.183 & 0.797 & 1.492 & 659.441 & 0.997 \\
\hline & $\mathrm{Ca}^{2+}$ & 2.420 & 0.190 & 0.770 & 1.496 & 551.735 & 0.989 \\
\hline & $\mathrm{PO}_{4}^{3-}$ & 2.444 & 0.197 & 0.744 & 1.492 & 454.364 & 0.971 \\
\hline \multirow[t]{4}{*}{ PHE } & None & 1.446 & 0.302 & 0.732 & 0.863 & 67.160 & 0.917 \\
\hline & $\mathrm{Mg}^{2+}$ & 1.404 & 0.313 & 0.763 & 0.826 & 61.612 & 0.931 \\
\hline & $\mathrm{Ca}^{2+}$ & 1.367 & 0.327 & 0.742 & 0.796 & 54.811 & 0.910 \\
\hline & $\mathrm{PO}_{4}^{3-}$ & 1.251 & 0.409 & 0.827 & 0.676 & 32.277 & 0.936 \\
\hline
\end{tabular}


In the presence of competing ions (i.e. $\mathrm{Mg}^{2+}, \mathrm{Ca}^{2+}$ and $\mathrm{PO}_{4}{ }^{3-}$ ), the adsorption of all pollutants (BEN, NAP and PHE) onto CTF-m could hardly be affected, except the slight decrease in PHE adsorption. This was likely due to that PHE was prone to be ionized to phenolate anion, which made it be more susceptible than BEN and NAP to be interfered by the changed local charge concentration. However, the $q_{\mathrm{m}}$ of PHE on CTF-m were still as high as $0.826,0.796$ and $0.676 \mathrm{mmol} / \mathrm{g}$ in the presence of $\mathrm{Mg}^{2+}$, $\mathrm{Ca}^{2+}$ and $\mathrm{PO}_{4}{ }^{3-}$, respectively, which were close to the value $(0.863 \mathrm{mmol} / \mathrm{g})$ without competing ions.

Table S-11. Influence of Competing Ions on the Percentage Regenerated of Adsorption Capacity for Benzene (BEN) onto CTF-m in the $2^{\text {nd }}$ Cycle of Photocatalytic Regeneration.

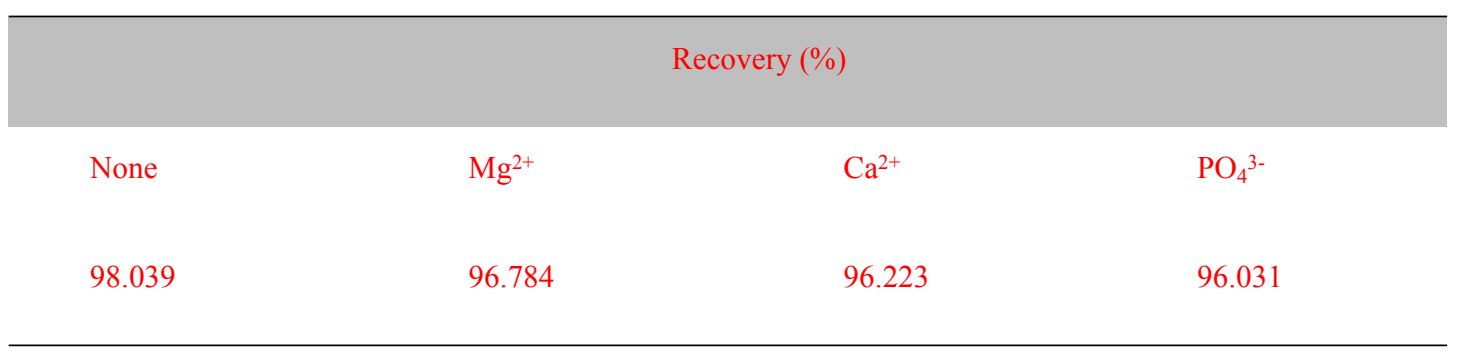

In the case of photocatalytic regeneration of CTF-m with competing ions, percentages regenerated of adsorption capacity of CTF-m in the $2^{\text {nd }}$ cycle were 96.784 $\%\left(\mathrm{Mg}^{2+}\right), 96.223 \%\left(\mathrm{Ca}^{2+}\right)$ and $96.031 \%\left(\mathrm{PO}_{4}^{3-}\right)$ for $\mathrm{BEN}$, which were comparable with the value $(98.039 \%)$ in the absence of competing ions, implying the little influence of competing ions on photocatalytic regeneration. 
Table S-12. Adsorption Isotherms of Benzene (BEN), Naphthalene (NAP) and Phenol (PHE) onto CTF-m in Solution of Individual Pollutant and Mixed Pollutants Fitted by the Freundlich and Langmuir Models.

\begin{tabular}{|c|c|c|c|c|c|c|c|}
\hline \multirow[b]{2}{*}{ Pollutant } & \multirow[b]{2}{*}{ Condition } & \multicolumn{3}{|l|}{ Freundlich Model } & \multicolumn{3}{|c|}{ Langmuir Model } \\
\hline & & $\begin{array}{l}K_{\mathrm{f}} \\
\left((\mathrm{mmol} / \mathrm{g}) /(\mathrm{mmol} / \mathrm{L})^{1 / \mathrm{n}}\right)\end{array}$ & $N$ & $R^{2}$ & $\begin{array}{l}q_{\mathrm{m}} \\
(\mathrm{mmol})\end{array}$ & $K_{\mathrm{L}}(\mathrm{L} / \mathrm{g})$ & $R^{2}$ \\
\hline \multirow[t]{2}{*}{ BEN } & Individual & 5.224 & 0.348 & 0.792 & 3.026 & 53.427 & 0.921 \\
\hline & Mixed & 3.965 & 0.444 & 0.854 & 2.232 & 23.810 & 0.935 \\
\hline \multirow[t]{2}{*}{ NAP } & Individual & 2.402 & 0.183 & 0.802 & 1.490 & 666.661 & 0.996 \\
\hline & Mixed & 1.330 & 0.442 & 0.916 & 0.647 & 31.658 & 0.982 \\
\hline \multirow[t]{2}{*}{ PHE } & Individual & 1.446 & 0.302 & 0.732 & 0.863 & 67.160 & 0.917 \\
\hline & Mixed & 1.285 & 0.512 & 0.951 & 0.669 & 16.807 & 0.980 \\
\hline
\end{tabular}

In comparison with individual adsorption $(3.026 \mathrm{mmol} / \mathrm{g}$ for BEN, $1.490 \mathrm{mmol} / \mathrm{g}$ for NAP, and $0.863 \mathrm{mmol} / \mathrm{g}$ for PHE), the adsorption capacity of BEN, NAP and PHE 
in the mixture decreased to $2.232 \mathrm{mmol} / \mathrm{g}$ for BEN, $0.647 \mathrm{mmol} / \mathrm{g}$ for NAP and 0.669 $\mathrm{mmol} / \mathrm{g}$ for PHE, respectively, which could be attributed to the competitive adsorption among them. Considering that the both BEN and NAP molecules adsorbed on the CTF-m surface via a tiled form of face-to-face adsorption by $\pi-\pi$ EDA interaction, the benzene ring sites (including unbroken benzene rings and broken benzene rings) on CTFm surface should be the main competition sites for BEN and NAP adsorption. Meanwhile, each BEN or NAP molecule would occupy 1 or 2 benzene ring sites, respectively. Given the facts above, we calculated the occupied sites in the adsorption process. The benzene ring sites of CTF-m occupied by BEN and NAP in the mixture was about $2.232 \mathrm{mmol} / \mathrm{g}+0.647 * 2 \mathrm{mmol} / \mathrm{g}=3.526 \mathrm{mmol} / \mathrm{g}$, which was higher than that occupied by individual BEN (3.026 mmol/g). This finding implied that, in the mixture of pollutants, the available sites of CTF-m had been used completely by pollutants, and the competition of different pollutants had mild facilitation to their adsorption onto CTF-m. In contrast, the PHE adsorption that underwent different mechanism from BEN and NAP adsorption had minimum reduction. This was reasonable since PHE molecules were obliquely adsorbed on the CTF-m surface by hydrogen bonding interaction, as discussed in the MS, which could be less affected by the other two pollutants. It should be noted that the sum of adsorption capacity of BEN, NAP and PHE in the mixture exceeded any individual adsorption, implying the excellent adsorption ability of CTF-m in the mixture. 
Table S-13. Influence of Mixture of Pollutants on the Percentage Regenerated of Adsorption Capacity for Benzene (BEN) onto CTF-m in the $2^{\text {nd }}$ Cycle of Photocatalytic Regeneration.

\begin{tabular}{cccc}
\hline & & Recovery (\%) & \\
& BEN & NAP & PHE \\
Individual & 98.039 & 98.780 & 97.143 \\
Mixed & 93.332 & 95.243 & 86.671 \\
\hline
\end{tabular}

The photocatalytic regeneration of CTF-m has also been investigated in the mixture of BEN, NAP and PHE. In the $2^{\text {nd }}$ cycle, the recovery percentage of adsorption capacity of CTF-m were $93.332 \%, 95.243 \%$ and $86.671 \%$ for BEN, NAP and PHE, respectively, which were comparable with the values $(98.039 \%$, $98.780 \%$ and $97.143 \%$ ) of counterparts in three individual pollutant. 


\section{References}

1. Yang, S.; Gong, Y.; Zhang, J.; Zhan, L.; Ma, L.; Fang, Z.; Vajtai, R.; Wang, X.; Ajayan, P. M. Exfoliated graphitic carbon nitride nanosheets as efficient catalysts for hydrogen evolution under visible light. Adv. Mater. 2013, 25 (17), 2452-2456.

2. Chengteh, L.; Weitao, Y.; Parr, R. G. Development of the Colle-Salvetti correlation-energy formula into a functional of the electron density. Phys. Rev. B 1988, $37(2), 785-789$. 
3. Goerigk, L.; Grimme, S. A thorough benchmark of density functional methods for general main group thermochemistry, kinetics, and noncovalent interactions. Phys. Chem. Chem. Phys. 2011, 13 (14), 6670-6688.

4. Grimme, S.; Antony, J.; Ehrlich, S.; Krieg, H. A consistent and accurate ab initio parametrization of density functional dispersion correction (DFT-D) for the 94 elements H-Pu. J. Chem. Phys. 2010, 132 (15), 154104.

5. Grimme, S. Semiempirical GGA-type density functional constructed with a long-range dispersion correction. J. Comput. Chem. 2006, 27 (15), 1787-1799.

6. Klamt, A.; Schuurmann, G. Cosmo: a new approach to dielectric screening in solvents with explicit expressions for the screening energy and its gradient. J. Chem. Soc., Perkin Trans. 2 1993, 5, 799-805.

7. Cammi, R.; Mennucci, B.; Tomasi, J. Second-order Moller-Plesset analytical derivatives for the polarizable continuum model using the relaxed density approach. $J$. Phys. Chem. A 1999, 103 (45), 9100-9108.

8. Tomasi, J.; Mennucci, B.; Cammi, R. Quantum mechanical continuum solvation models. Chem. Rev. 2005, 105 (8), 2999-3093.

9. Frisch, M. J.; Trucks, G. W.; Schlegel, H. B.; Scuseria, G. E.; Robb, M. A.; Cheeseman, J. R.; Scalmani, G.; Barone, V.; Mennucci, B.; Petersson, G. A. Gaussian 09, Revision A. 1, Gaussian, Inc., Wallingford CT, 2009.

10. Lan, Z.-A.; Fang, Y.; Zhang, Y.; Wang, X. Photocatalytic oxygen evolution from functional triazine-based polymers with tunable band structures. Angew. Chem. Int. Edit. 2018, 57 (2), 470-474.

11. Huang, W.; Wang, Z. J.; Ma, B. C.; Ghasimi, S.; Gehrig, D.; Laquai, F.; Landfester, K.; Zhang, K. A. I., Hollow nanoporous covalent triazine frameworks via acid vapor-assisted solid phase synthesis for enhanced visible light photoactivity. $J$. Mater. Chem. A 2016, 4 (20), 7555-7559. 
12. Bui , T. D.; Kimura, A.; Higashida, S.; Ikeda, S.; Matsumura, M. Two routes for mineralizing benzene by $\mathrm{TiO}_{2}$-photocatalyzed reaction. Appl. Catal., B 2011, 107, $119-127$.

13. Xia, S.; Zhang, L.; Zhou, X.; Shao, M.; Pan, G.; Ni, Z. Fabrication of highly dispersed $\mathrm{Ti} / \mathrm{ZnO}-\mathrm{Cr}_{2} \mathrm{O}_{3}$ composite as highly efficient photocatalyst for naphthalene degradation. Appl. Catal., B 2015, 176-177, 266-277.

14. Katekomol, P.; Roeser, J.; Bojdys, M.; Weber, J.; Thomas, A. Covalent triazine frameworks prepared from 1,3,5-tricyanobenzene. Chem. Mater., 2013, 25, 1542-1548. 